$\Phi=5$

\title{
Toxic effects of plastic on human health and environment : A consequences of health risk assessment in Bangladesh
}

\author{
Ram Proshad ${ }^{1}$ *, Tapos Kormoker ${ }^{2}$, Md. Saiful Islam ${ }^{1}$, Mohammad Asadul Haque', \\ Md. Mahfuzur Rahman', Md. Mahabubur Rahman Mithu ${ }^{3}$ \\ ${ }^{1}$ Department of Soil Science, Patuakhali Science and Technology University, Dumki, Patuakhali-8602, Bangladesh \\ 2 Department of Emergency Management, Patuakhali Science and Technology University, Dumki, Patuakhali-8602, Bangladesh \\ ${ }^{3}$ Faculty of Nutrition and Food Science, Patuakhali Science and Technology University, Dumki, Patuakhali-8602, Bangladesh \\ *Corresponding author E-mail: ramproshadpstu03470@gmail.com
}

\begin{abstract}
Plastics are used widely everywhere in our life and without plastic, modern civilization would indeed look very diverse. This study focuses on the toxic effects of plastic on human health and environment and possible consequences of health risk assessment in Bangladesh. Plastics are essential materials in modern civilization, and many products manufactured from plastics and in numerous cases, they promote risks to human health and the environment. Plastics are contained many chemical and hazardous substances such as Bisphenol A (BPA), thalates, antiminitroxide, brominated flame retardants, and poly- fluorinated chemicals etc. which are a serious risk factor for human health and environment. Plastics are being used by Bangladeshi people without knowing the toxic effects of plastic on human health and environment. Different human health problems like irritation in the eye, vision failure, breathing difficulties, respiratory problems, liver dysfunction, cancers, skin diseases, lungs problems, headache, dizziness, birth effect, reproductive, cardiovascular, genotoxic, and gastrointestinal causes for using toxic plastics. Plastics occur serious environment pollution such as soil pollution, water pollution, and air pollution. Application of proper rules and regulations for the production and use of plastics can reduce toxic effects of plastics on human health and environment.
\end{abstract}

Keywords: Plastic; Bisphenol A; Phthalates; Pollution; Bangladesh.

\section{Introduction}

Plastic has changed our everyday life. We are involved with plastic made products in various ways. Plastic plays an important part in our life. Plastics are used widely everywhere in our life. Plastic makes our life easier and better. They are composed of a network of molecular monomers bound together to form macromolecules of infinite use in human society. Day by day peoples are becoming more and more dependent on the use of plastics because of the characteristics of plastic such as inert, durability, flexibility and versatility and so on. The durability of plastics and their potential for diverse applications, including widespread use of disposable items, were anticipated, but the problems associated with waste management and plastic debris were not (Yarsley \& Couzens 1945). Plastic has some special properties such as; high heat combustion, the water content of the plastics is far lower than the water content in the biomass, plastics do not absorb much moisture and increasing availability in the local community. Plastics have many benefits and without plastic, modern society would indeed look very different. Most important advantages of plastic are medical uses and applications in public health. Plastics are costeffective, require little energy to produce, and are lightweight and biocompatible. Plastic is soft, transparent, flexible, or biodegradable and many different types of plastics function as innovative materials for use in engineered tissues, absorbable sutures, prosthetics, and other medical applications (Andrady \& Neal 2009). However, plastics also have numerous disadvantages, such as toxic substances that may leak out and adversely affect humans and other organisms. There are about 20 types of prime plastics use in the worldwide (APME 2006). Scientists have shown in the study that the use of plastic bottles or containers increases health risk due to long-term use. Typically, there are many chemical substances present in plastic bottles or containers, many of which are a serious risk factor for health. For example, potentially dangerous human exposure to toxic components such as Bisphenol A (BPA), thalates, antiminitroxide, brominated flame retardants, and poly-fluorinated chemicals etc. are notable (Halden 2010). BPA and phthalates are found in many mass-produced products including medical devices, food packaging, perfumes, cosmetics, toys, flooring materials, computers and CDs and can represent a significant content of the plastic. For instance, phthalates can constitute a substantial proportion, by weight, of PVC while BPA is the monomer used for the production of polycarbonate plastics as well as an additive used for the production of PVC. Phthalates can leach out of products because they are not chemically bound to the plastic matrix, and they have attracted particular attention because of their high production volumes and wide usage (Wagner \& Oehlmann 2009). Phthalates and BPA are detectable in aquatic environments, in dust and, because of their volatility in the air (Rudel et al. 2001; 2003). There is considerable concern about the adverse effects of these chemicals on wildlife and humans (Meeker et al. 2009). It may be a great concern to use and disposal of plastic. Worldwide polymer production was estimated to be 260 million metric tons per annum in the year 2007 for all polymers including thermoplastics, thermoset plastics, adhesives, and coatings, but not synthetic fibers (Plastics Europe 2008). This indicates a historical 
growth rate of about 9 percent p.a. Thermoplastic resins constitute around two-thirds of this production and their usage is growing at about 5 percent globally. Approximately 50 percent of plastics are used for single-use disposable applications, such as packaging, agricultural films and disposable consumer items, between 20 and 25 percent for long-term infrastructure such as pipes, cable coatings and structural materials, and the remainder for durable consumer applications with intermediate lifespan, such as in electronic goods, furniture, vehicles, etc. Post-consumer plastic waste generation across the European Union (EU) was 24.6 million tons in 2007 (Plastics Europe 2008). The plastic industry in Bangladesh uses imported polymer granules. During the period 1989 to 2007 , the import of polymers increased from 10,000 tons to 289,000 tons per year. At present total consumption of polymers including imported polymers and recycled plastic wastes is 750,000 tons in FY 2010-2011. This corresponds to the per capita consumption of plastics in Bangladesh $5 \mathrm{~kg}$ per year against the world average $30 \mathrm{~kg}$. Per capita consumption in India and ASEAN countries are $8 \mathrm{~kg}$ and $17 \mathrm{~kg}$ respectively. Quite a few decades ago, Bangladesh was not familiar with the multiple uses of plastics. But in recent years, particularly its large cities have experienced a widespread and growing use of plastic products. As a result, Bangladesh is also facing all of the environmental, economic and health problems caused by plastic pollution. Taking the environmental issue into account, Bangladesh government imposed a ban on poly bags on 1st March 2002. But, unfortunately, of late polybag and other poly products are gradually coming backing in business. Notwithstanding the current relatively low use of plastic products, this is an opportune time for policymakers to formulate measures and for general users to change their habit and choice to environment-friendly natural fiber products as practical alternatives. Otherwise, the longer we shall wait, the more difficult it will be to change people's habit.

\section{Categories of plastics}

\subsection{Type 1 polyethylene terephthalate or stomach plas- tic}

Stomach plastic is usually used to make disposable water bottles Apart from this, stomach plastics are used to make different utensils or containers used for various types of juice, soft drinks, butter, salad dressing, vegetable oil, mouthwash, cosmetics etc. The stomach plastic weight is thin, transparent and smooth. Due to being fully liquid and anti-inflammatory, the stomach is very popular among plastic water and another food packaging. Being antiair, the stomach plastic prevented the entry of oxygen. Drinking or liquids are not easily washed inside the stomach bottles. Type 1 plastic bottle does not have any harmful bacteria or thalates, but its use is used in antimony trioxide. Antimony acts as a possible carcinogen in the human body. Antimony is emitted from the container for long periods of contact with drinking water. As long as the beverage is in contact with the container, the likelihood of antimony excretion increases. It has been found in the study that the use of long-time heat is toxic antimony from the stomach bottle. So it is vital to keep these stomach bottles away from high temperatures. Note that type 1 or stomach plastic is prepared for 'once use only' (one time use only). The stomach bottle is relatively safe in the 'once used' field.

\subsection{Type 2 High-density polyethylene}

Polyethylene is the most used plastic in the world. High-density polyethylene made from petroleum, a type of heat-resistant plastic. Type 2 plastic is used in making milk containers, detergent bottles, refrigerators, toys, various types of plastic grocery bags, etc. Highdensity polyethylene is relatively strong, irritable and 'heat-prone' in nature. It does not contain harmful BPA or thalates. There is no known health risk for this type of plastic use. Although some studies have shown, if the sunlight is kept in a long time, then the nanalifenal is extracted from type 2 plastic to ultraviolet rays. Compared to type 1 , type 2 container is considered safer for food and drink

\subsection{Type 3 plastic containers}

They are used for fruit juice, cooking oil etc. Polyvinyl Chloride (PVC) is a type of 'heat-resistant' polymer. Depending on nonplasticization, type 3 plastic is flexible and unobtrusive. Normally the thalates are used to make PVC flexible, which is harmful to the human body. Plasticized PVC pipes and siding also have thalates. PVC contains many toxic chemical substances such as BPA, thalates, led, dioxin, crater, and cadmium. The whole life cycle of PVC, production, use and disposable is related to severe health risks and environmental pollution, due to which PVC use has reduced considerably. However, because of the cost-effective and versatile use, PVC is still very popular in the case of consumer products. Due to poisonous use of PVC plastic due to health risk and environmental pollution. It can cause cancer, birth defects, genetic changes, chronic bronchitis, ulcers, skin diseases, deafness, vision failure, indigestion, and liver dysfunction.

\subsection{Type 4 low-density polyethylene}

A type of 'heat-resistant' polymer made of type 4 plastic petroleum, which can be both transparent and opaque. Low-density polyethylene is flexible and rigid but fragile. These plastic are used in packaging of frozen foods and preparation of juices and milk cartons. There is no loss of contact with the container or bottled fluid. Because the type 4 plastic containers do not contain any harmful components of the human body, their use is safe for food and beverages.

\subsection{Type 5 polypropylene}

Polypropylene is a type of plastic polymer, usually strong and semi-transparent, strong, high in heat and hydrophobic. They are stronger and heavier than polyethylene. Polypropylene is commonly used for packing yogurt, medicine, beverage, ketchup etc. It should be noted here that no harmful substances are found in food or water from polypropylene plastic. Most polypropylene plastic is microwaveable and washing with dishwasher, but they do not cause any harm. Like type 4 plastic, polypropylene containers are not harmful, they are considered safe for the human body for food and beverages.

\subsection{Type 6 polystyrene}

Polyethylene is one type of petroleum-based plastic. 'Benzene' is used in the preparation of polystyrene, which is known as a carcinogen for the human body. Polystyrene is widely used in making packaging materials and insulating. Styrene is very risky for health Studies have shown that, due to long exposure, steroid also provides neurotoxic, hematological, cytogenetic and carcinogenic effects. The International Agency for Research on Cancer (IARC) identified Styrene as the human carcinogen.

\subsection{Type 7 polycarbonate}

Except for the type mentioned, all plastics are labeled as Type 7 plastics. Polycarbonate container is made of BPA. So, the beverage or food stored in them, the BPA is released from the container. Due to the BPA's health risk being proven in multiple studies, the use of type 7 or polycarbonate plastic has recently decreased greatly. Polycarbonate is basically used for packaging consumer goods. Type 7 plastic is used in baby bottles, 3 and 5 gallons of bottles (reusable) etc. Due to health risk type 7 or polycarbonate plastic use is unsafe. 


\section{Effects of plastic on human health}

Human health risks from plastics can stem from their monomeric building blocks (e.g., Bisphenol A), their additives (e.g., plasticizers) or from a combination of the two (e.g., antimicrobial polycarbonate) (Rahman \& Brazel 2004). There are several toxic materials which are secreted by plastics. Among them, we concentrate on plastics components and additives of principal concern such as Bisphenol A and phthalates. Bisphenol A (BPA) is best known as the monomeric building block of polycarbonate plastics. It was first synthesized in 1891 and used frequently as an additive to other plastics such as polyvinyl chloride (PVC) (Dodds \& Lawson 1936). The annual output of BPA in the worldwide was 2.2 million metric tons in 2003. A sizable fraction of this mass comes into contact with food. Because the polymerization of BPA leaves some monomers unbound, BPA molecules can be released from beverage and food containers into drink and food over time. The leaching process is accelerated by repeated washing of containers and when storing in the acidic or basic items that break down the polymer. As a result, reusable water bottles, baby bottles, and the inner linings of food cans, all made by using BPA, are known to leach the controversial monomer into food over time, particularly at elevated temperatures (Raloff 1999; Kang et al. 2003). Studies have indicated that food and drinks stored in such containers including those ubiquitous clear water bottles hanging from just about every hiker's backpack can contain a trace amount of Bisphenol A (BPA) that may interfere with the body's natural hormonal messaging system. Food and inhalation are considered the main source of exposure to BPA in the human body (Wilson et al. 2007). The BPA is considered to be a hormone because it is the mimics of reproductive hormones 'estrogen'. As found in various studies, BPA has been associated with a number of health problems such as ovarian chromosomal damage, decreased sperm production, rapid puberty, rapid changes in immune system, type-2 diabetes, cardiovascular disorder, obesity etc. Some studies have also claimed that BPA increases the risk of breast cancer, prostate cancer, pains, metabolic disorders, etc. BPA in women and impaired health, including obesity, endometrial hyperplasia, recurrent miscarriages, sterility, and polycystic ovarian syndrome (Warner et al. 2002; Rayner et al. 2004; Eskenazi et al. 2007). Levels of unconjugated BPA in human blood and tissues are in the range of 0.1 to $10 \mu \mathrm{g} / \mathrm{L}$ in the human body and is assessed in blood serum and urine (Ikezuki et al. 2002; Schonfelder et al. 2002). BPA is determined by enzyme-linked immune sorbent assay (ELISA). Geometric means for daily intake of BPA estimated from urinary levels are higher for males than females $(53.8$ versus $41 \mathrm{ng} / \mathrm{kg} /$ day) and higher in children and adolescents (64.6 and $71 \mathrm{ng} / \mathrm{kg} / \mathrm{day}$, respectively) than in adults, whose exposure levels decrease with age from $52.9 \mathrm{ng} / \mathrm{kg} /$ day in 20-39-year olds to $33.5 \mathrm{ng} / \mathrm{kg} /$ day in seniors 60 years and older (Lakind \& Naiman 2008). Elevated exposure of women of childbearing age and of children are of particular concern because of known windows of vulnerability to BPA that put the developing fetus and children at elevated risk, compared with adults exposed to identical levels of the contaminant (Vandenberg et al. 2009).

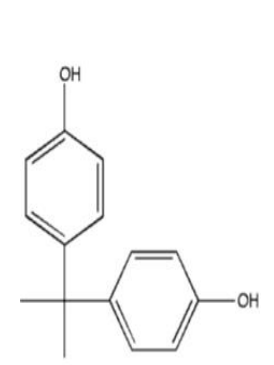

Bisphenol A

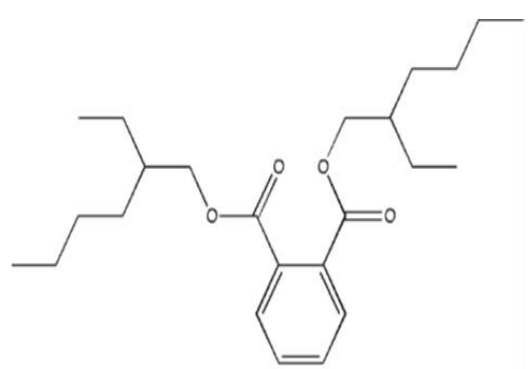

Di(2-ethylhexyl) phthalate

Fig. 1: Chemical Structures of Bisphenol A and Di-(2-Ethylhexyl) Phthalate (DEHP), which Illustrate the Use of Endocrine-Disrupting Monomers and Plasticizers in Contemporary Plastics.
In its determination of a reference dose for humans, the U.S. EPA arrived at a value of $50 \mu \mathrm{g}$ per $\mathrm{kg}$ per day by applying a safety factor, to account for extrapolation from animals to humans, variability in the human population, and extrapolation from subchronic to chronic exposures (Welshons et al. 2003). This reference dose for BPA was calculated on the basis of the lowest observable adverse effect level (LOAL) as adverse responses were found even at the lowest dose tested (Vandenberg et al. 2009). Today's concerns about BPA are driven primarily by low-dose effects observed in human populations, and by the recognition that biologically active levels of BPA detectable in human blood are within or above the range of concentrations demonstrated in vitro to cause changes in the function of human tissues (Vom \& Hughes 2005). Phthalates are a diverse group of compounds that represent diesters of phthalic acid, a compound also known as 1, 2benzenedicarboxylic acid produced in large quantities since the 1930s. The properties of phthalates are dependent on the length and branching of the dialkyl or alkyl/aryl side chains, i.e., the alcohol moiety of the ester. Di (2-ethylhexyl) phthalate (DEHP), produced at annual quantities of 2 million tons and widely used in medical devices. Important routes of human exposure to phthalates include, most notably, medical exposures caused by direct release of phthalates into the human body, e.g., through dialysis, blood transfusions, and extracorporeal membrane oxygenation (ECMO); ingestion of contaminated materials, including contaminated food, house dust etc. (Sathyanarayana 2008; Kamrin 2009; Meeker et al. 2009). Thalates usually work to increase plastic flexibility or flexibility. Here is an example of adding some plastic such as polyvinyl chloride (PVC) thalates. Thales like BPA has hormonal imbalances, which also cause them to disrupt hormones normal and daily work. Both BPA and thalates can enter the body of the newborn through pregnancy and through fetal and breastfeeding, they will be able to harm them. However, it is important to remember that, Thales is a little less damaging to human than the BPA. So all kinds of plastic containers have harmful BPA and thalates.

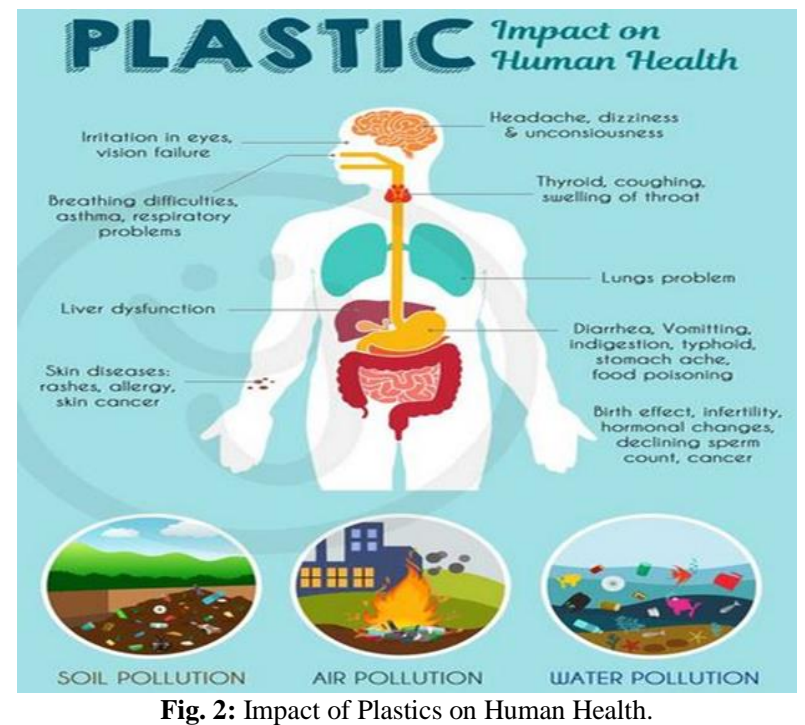

\section{Effects of plastic on the environment}

The distribution of plastic debris is highly variable as a result of certain factors such as wind and ocean currents, urban areas, and trade routes. Human population in certain areas also plays a large role in this plastics can also be used as vectors for chemical contaminants such as persistent organic pollutants and heavy metals (Barnes et al. 2009). Toxic chemical release during manufacture is another significant source of the negative environmental impact of plastics. A whole host of carcinogenic, neurotoxic, and hormonedisruptive chemicals are standard ingredients and waste products of plastic production, and they inevitably find their way into our 
ecology through water, land, and air pollution. Some of the more familiar compounds include vinyl chloride (in PVC), dioxins (in PVC), benzene (in polystyrene), phthalates and other plasticizers (in PVC and others), formaldehyde, and Bisphenol-A, or BPA (in polycarbonate). Many of these are persistent organic pollutants (POPs) - some of the most damaging toxins on the planet, owing to a combination of their persistence in the environment and their high levels of toxicity. Their unmitigated release into the environment affects all terrestrial and aquatic life with which they come into contact. The manufacturing process of plastic products in plastic industries releases a huge quantity of dangerous gaseous chemicals into the air including carbon monoxide, dioxin, and hydrogen cyanide. These gases pollute air seriously. The presence of these gases in air at high proportion is detrimental to both human and animal health. They may cause respiratory diseases, nervous system disorders and reduction in immunity to diseases. Chlorinated plastic can release harmful chemicals into the surrounding soil, which can then seep into groundwater or other surrounding water sources and also the ecosystem. This can cause serious harm to the species that drink the water. Landfill areas contain many different types of plastics. In these landfills, there are many microorganisms which speed up the biodegradation of plastics. The microorganisms include bacteria such as Pseudomonas, nylon-eating bacteria, and Flavobacteria. These bacteria break down nylon through the activity of the nylonase enzyme. When biodegradable plastics are broken down, methane is released, which is a very powerful greenhouse gas that contributes significantly to global warming (Biello 2013). Apart from the above impacts, some scientists believe that the bobbing bits of polymer in the oceans could contribute to global warming by creating a shaded canopy that makes it harder for plankton to grow. It needs no telling that the plant kingdom is the universal carbon sink. We are facing a serious problem of water pollution by plastic waste. Very often we dispose of discarded plastic products in different water bodies including lakes, rivers, ponds, etc. The lakes in the megacity of Dhaka may be the best example of pollution by plastic bottles, canes, bags and other plastic products frequently thrown by the visitors. The presence of plastic wastes in water bodies disturbs the natural flow, limits the ability of fish to reproduce and destroys helpful organisms.

\section{Answerable organizations and rules for re- ducing plastic toxicity in Bangladesh}

The government faces a major challenge for the proper management of plastics in Bangladesh. In respect of human health and environment pollution related concerns, several rules and regulations have been issued and implemented in developing and developed countries due to control the production and use of plastic materials. Bangladeshi organizations and agencies are responsible ensuring the sustainable production, use, and disposal of plastic and plastic materials like Bangladesh Ministry of Environment and Forest, Ministry of Health, Mobile court. Bangladesh was the first country to ban plastic bags to control environmental pollution and over a decade later several developed countries are still struggling to emulate this achievement. The Environment Conservation Act was formulated in Bangladesh in 1995. The law of section 1 under this act was reviewed in 2002. According to Rule 6ka of Clause-5 under Section-9, the constraint has been enacted in the production and uses of polythene shopping bag. According to the rule, there is restriction on the production and sale of environmentally detrimental products. If it is proven that any kind of plastic bags or products made of polyethylene or poly-propylene is detrimental for the environment then the government could control or ban the use of these products to any selected area or all over the country. According to rule $6 \mathrm{ka}$, the penalty and punishment will be:

$\square$ For production, import and marketing - 10 years sentence of vigorous prison, or 1 million taka fine, or both punishments together.
For sale, exhibition for sale, store, distribution, transportation or use for commercial purpose -6 months sentence of vigorous prison or 10 thousand taka fine, or both punishments together.

\section{Conclusions}

Toxicity of plastic is a problem in nature on a universal scale, from the individual level to the level of populations. The study reveals that the negative consequences of plastic on human health and environment as a result of exposure to toxic chemicals used in the production of plastics. Peoples of Bangladesh unconsciously used those plastics without knowing its toxicity. The toxic effect of plastics on human health and environment is very much evident by the most of the reviews. The government, law implementing agencies and health authorities of the country should take more steps and pay attention to sustainable production, use, and disposal of plastics. Phthalates of high concern should be banned and implemented, primary in consumer products or product in contact with children. Bisphenols should be forbidden from use in materials that come into contact with food and beverages and children and in the long term in other consumer products like thermal cash receipt. Every company must take their responsibility in terms of the reduction of unnecessary plastic consumption. A full of information about all existing chemicals in consumer products must be required so that peoples becomes aware to use of those products.

\section{Acknowledgement}

The authors thank the authority of Patuakhali Science and Technology University (PSTU), Bangladesh for supporting to complete this study.

\section{References}

[1] Andrady A (2003), an environmental primer. In Plastics and the environment (ed. Andrady A., editor.), pp. 3-76 Hoboken, NJ Wiley Interscience.

[2] Andrady AL \& Neal MA (2009), Applications and societal benefits of plastics. Phil. Trans. R. Soc. B 364, 1977-1984 (doi:10.1098/rstb.2008.0304). https://doi.org/10.1098/rstb.2008.0304.

[3] APME (2006), an Analysis of Plastics Production, Demand and Recovery in Europe.

[4] Barnes DKA, Galgani F, Thompson RC \& Barlaz M (2009), Accumulation and fragmentation of plastic debris in global environments. Philosophical Transactions of the Royal Society B: Biological Sciences. 364 (1526), 1985-1998. https://doi.org/10.1098/rstb.2008.0205.

[5] Biello \& David (2011), Are Biodegradeable Plastics Doing More Harm Than Good? Scientific American. Retrieved 1 August 2013.

[6] Dodds EC \& Lawson W (1936), Synthetic estrogenic agents without the phenantthrene nucleus. Nature 137, 996. https://doi.org/10.1038/137996a0.

[7] Eskenazi B, Warner M, Samuels S, Young J \& Gerthoux PM (2007), Serum dioxin concentrations and risk of uterine leiomyoma in the Seveso Women's Health Study. American Journal of Epidemiology 166, 79-87. https://doi.org/10.1093/aje/kwm048.

[8] Halden RU (2010), Plastics and health risks. Annu Rev Public Health

31(1) 179-194. https://doi.org/10.1146/annurev.publhealth.012809.103714

[9] Ikezuki Y, Tsutsumi O, Takai Y, Kamei Y \& Taketani Y (2002), Determination of bisphenol a concentrations in human biological fluids reveals significant early prenatal exposure. Hum. Report 17 2839-2841. https://doi.org/10.1093/humrep/17.11.2839.

[10] Kamrin MA (2009), Phthalate risks, phthalate regulation, and public health: a review. J. Toxicol. Environ. Health B 12,157-74. https://doi.org/10.1080/10937400902729226.

[11] Kang JH, Kito K \& Kondo F (2003), Factors influencing the migration of bisphenol A from cans. J. Food Prot. 66, 1444-1447. https://doi.org/10.4315/0362-028X-66.8.1444.

[12] Lakind JS \& Naiman DQ (2008), Bisphenol A (BPA) daily intakes in the United States: estimates from the 2003-2004 NHANES urinary BPA data. J. Expo. Sci. Environ. Epidemiol. 18, 608-15. https://doi.org/10.1038/jes.2008.20. 
[13] Meeker JD, Sathyanarayana S \& Swan SH (2009), Phthalates and other additives in plastics: human exposure and associated health outcomes. Phil. Trans. R. Soc. B 364, 2097-2113 (doi:10.1098/rstb.2008.0268). https://doi.org/10.1098/rstb.2008.0268.

[14] Plastics Europe (2008), the compelling facts about Plastics 2007: an analysis of plastics production, demand and recovery for 2007 in Europe. Brussels, Belgium: Plastics Europe.

[15] Rahman M \& Brazel CS (2004), the plasticizer market: an assessment of traditional plasticizers and research trends to meet new challenges. Prog. Polym. Sci. 29, 1223-48. https://doi.org/10.1016/j.progpolymsci.2004.10.001.

[16] Raloff J (1999), Food for thought: What's coming out of baby's bottle? Sci. News Online 156, 1-4.

[17] Rayner JL, Wood C \& Fenton SE (2004), Exposure parameters necessary for delayed puberty and mammary gland development in Long-Evans rats exposed in utero to atrazine. Toxicol. Appl. Pharmacol. 195, 23-34. https://doi.org/10.1016/j.taap.2003.11.005.

[18] Rudel RA, Dodson RE, Newton E, Zota AR \& Brody JG (2008), Correlations between urinary phthalate metabolites and phthalates, estrogenic compounds 4-butyl phenol and o-phenyl phenol, and some pesticides in home indoor air and house dust. Epidemiology 19, S332.

[19] Sathyanarayana S (2008), Phthalates and children's health. Curr. Probl. Pediatr. Adolesc. Health Care 38, 34-49. https://doi.org/10.1016/i.cppeds.2007.11.001.

[20] Schonfelder G, Wittfoht W, Hopp H, Talsness CE, Paul M \& Chahoud I (2002), Parent bisphenol A accumulation in the human maternal-fetal-placental unit. Environ. Health Perspect. 110, 703-707. https://doi.org/10.1289/ehp.021100703.

[21] Vandenberg LN, Maffini MV, Sonnenschein C, Rubin BS \& Soto AM (2009), Bisphenol-A and the great divide: a review of controversies in the field of endocrine disruption. Endocr. Rev. 30, 75-95. https://doi.org/10.1210/er.2008-0021.

[22] Vom Saal FS \& Hughes C (2005), an extensive new literature concerning low-dose effects of bisphenol A shows the need for a new risk assessment. Environ. Health Perspect. 113, 926-33. https://doi.org/10.1289/ehp.7713

[23] Wagner M \& Oehlmann J (2009), Endocrine disruptors in bottled mineral water: total estrogenic burden and migration from plastic bottles. Environ. Sci. Pollut. Res 16, 278-286. https://doi.org/10.1007/s11356-009-0107-7.

[24] Warner M, Eskenazi B, Mocarelli P, Gerthoux PM \& Samuels S (2002), Serum dioxin concentrations and breast cancer risk in the Seveso Women's Health Study. Environ. Health Perspect. 110, 625-28. https://doi.org/10.1289/ehp.02110625.

[25] Welshons WV, Thayer KA, Judy BM, Taylor JA, Curran EM \& Vom Saal FS (2003), large effects from small exposures. I. Mechanisms for endocrine-disrupting chemicals with estrogenic activity. Environ. Health Perspect. 111, 994-1006. https://doi.org/10.1289/ehp.5494.

[26] Wilson NK, Chuang JC, Morgan MK, Lordo RA \& Sheldon LS (2007), An observational study of the potential exposures of preschool children to pentachlorophenol, bisphenol-A, and nonylphenol at home and daycare. Environ. Res. 103, 9-20. https://doi.org/10.1016/j.envres.2006.04.006.

[27] Yarsley VE \& Couzens EG (1945), Plastics Middlesex: Penguin Books Limited. 